\title{
Molecular Simulation of Hyperbranched Polyester
}

Liu Yanmei ${ }^{a}$, Li Haihuab ${ }^{\text {, Tai Yuleic }}$, Chao Guoku ${ }^{d}$, Zhao Yajuan ${ }^{\text {** }}$

${ }^{a, b, c, d}$ College of Chemistry and Materials Science,Wenzhou University,Wenzhou, Zhejiang,325027,China

*E-mail: zyj@wzu.edu.cn

${ }^{a} E-m a i l:$ LiuYanMei198711@yeah.net

${ }^{b}$ E-mail: haizhifeng123@126.com

'E-mail: taiyulei@163.com

dE-mail: 46008906@qq.com

\section{ABSTRACT}

A new types of hyperbranched polyester was synthesized by the 2,2-bis(hydroxymethyl) propionic acid as an $A_{2}$-type monomer and glycerol as the core moiety. Molecular weights were confirmed by Gel Permeation Chromatography. Acid values were titrated by $\mathrm{KOH}$. The hydroxy value was obtained by titration. Furthermore, we calculate logarithmic value of acid value, hydroxy value, and molecular weight, respectively, and the simulation model curves were obtained. Based on the simulation model curves, we establish the empirical equation of the relationship of molecular weight, acid value and hydroxy value.

\section{Indexing terms/Keywords}

Hyperbranched; Molecular ; Acid value; Hydroxy value; Equation

\section{Academic Discipline And Sub-Disciplines}

Macromolecular Science

\section{SUBJECT CLASSIFICATION}

Hyperbranched Polyesters

\section{TYPE (METHOD/APPROACH)}

Synthesis, Characterization and Molecular Simulation

\section{Council for Innovative Research}

\author{
Peer Review Research Publishing System
}

Journal: Journal of Advances in Chemistry

Vol. 5, No. 1

editor@cirworld.com

www.cirworld.com, member.cirworld.com 


\section{INTRODUCTION}

Recently, dendritic polymer including dendrimers and hyperbranched polymer have received increasing attention due to their unique chemical and physical properties. Compared to traditional liner polymer, they have very large numbers of branch points and end groups, low viscosity and excellent solubility[1-6], such as polyesters[7-8], polyamids[9], polysioxysilanes[10] which have been report in past decades.Dendritic polymers mainly include dendrimers and hyperbranched polymers[11]. Dendritic polymer generally synthesized using a multi-step procedure[12-13], however, it is difficult to separate and purity the products. Hyperbranched polymers less regular structure and have more random branches relative to dendrimers, which can be synthesized by simple one-pot polymerization strategies such as polycondensation[14-17], living polymerization (atom transfer radical polymerization[18-19], reversible additionfragmentation-chain transfer[20]. However, many physical properties of hyperbranched macromolecules have not yet been investigated completely[21].Studies on molecular modeling through atomistic simulations would allow us to know some of their properties before we find their applications.

In this paper, a one-pot synthesis of hyperbranched polyesters by polycondensation using 2,2-bis(hydroxymethyl) propionic acid as an $\mathrm{AB}_{2}$-type monomerand and glycerol as the core moiety, is presented. Then acid values were titrated by $\mathrm{KOH}$. The hydroxy values were determined by acetylation of hydroxide groups with phthalic anhydride, which was hydroysed. This paper mainly study on the relationship between acid value, hydroxy value and molecular weight.

\section{EXPERIMMENTAL}

\subsection{Materials}

Dimethylol propionic acid,Glycerol, potassium hydroxide, pyridine(AR), phthalic anhydride, phenolphthalein, and potassium hydrogen phthalate were used as received

\subsection{Synthesis of hyperbranched polyester}

The reaction was conducted in a $1000 \mathrm{~mL}$ reaction kettle equipped with a nitrogen inlet tube, a reflux condenser, heating device and a vacuum device. The mixture of glycerol and 2,2-bis(hydroxymethyl) propionic acid (DMPA) was add to the reaction kettle, The reaction mixture was slowly heated $t 0190^{\circ} \mathrm{C}$ After the reactants were completely melted, The temperature was maintained between $190^{\circ} \mathrm{C}$ and $200^{\circ} \mathrm{C}$ with the continuous nitrogen flow for about $36 \mathrm{~h}$. We monitored the reaction periodically by determining the acid value and stopped reaction until the acid was stabilization. Then keep in vacuum for a certain time.

\subsection{Characterization}

\subsubsection{Acid value}

Acid value was determined by titrated by $\mathrm{KOH}$ using phenolphthalein as the indicator. In a typical titration procedure, milligrams $\mathrm{KOH}$ were required to neutralize free acids in $1 \mathrm{~g}$ hyperbranched polyester. sample was dissolved in ethanol and ether and neutralized with $\mathrm{KOH}$.The acid value, i.e., the total concentration of the carboxylic groups, was measured by diluting about $1 \mathrm{~g}$ of the sample to $60 \mathrm{~cm}^{3}$ neutralized distilled water, then the sample was titrated with $0.8185 \mathrm{~mol} / \mathrm{L} \mathrm{KOH}$.

\subsubsection{Hydroxy value}

The hydroxy value is usually determined by titration methods. The hydroxy value was determined by acetylation of the hydroxide groups with phthalic anhydride, which was hydrolysed. The excess acetic acid and the free acid groups in the reaction media were titrated with $\mathrm{KOH}$. The hydroxy value was determined with the acid value according to the ISO standard[23]

\subsubsection{Gel Permeation Chromatography(GPC)}

Weight-average molecular weight (Mw), number average molecular weight $(\mathrm{Mn})$ and dispersity $(\mathrm{D}=\mathrm{Mw} / \mathrm{Mn})$ were obtained using GPC instrument. GPC measurements were carried out using Waters 2414 Series (Japan) with a refractive index detector to determine the molecular weight of the polymer solutions. Samples were prepared in tetrahydrofuran (THF) solvent at a $3 \mathrm{mg} / \mathrm{mL}$ concentration. The columns were eluted using THF and calibrated with poly(methyl methacrylate) standards. All calibrations and analysis were performed at $40^{\circ} \mathrm{C}$ and the flow rate of the mobile phase was kept at 0.4 $\mathrm{mL} / \mathrm{min}$.

\subsubsection{NMR}

The ${ }^{1} \mathrm{H}$ and ${ }^{13} \mathrm{C}$ NMR spectra of the hyperbranched polyesters were recorded on Bruker UXNMR $300 \mathrm{MHz}$ spectrometers in dimethyl sulfoxide $d_{6}\left(D M S O-d_{6}\right)$ at ambient temperature.

\section{RESULTS AND DISCUSSION}

\subsection{The acid value, hydroxy value and the number average molecular weight}

Different hypherbranched polyesters were synthesis in different conditions, then acid value and hydroxy value was titrated by $\mathrm{KOH}$ and number average molecular weight $(\mathrm{Mn})$ was measured by GPC .The dates were shown in the Table 1 
Table1 The acid value, hydroxy value and Mn of as-obtained products

\begin{tabular}{|c|c|c|c|}
\hline experimental & Acid value & Hydroxy value & Mn \\
\hline 1 & 26.68 & 120.92 & 1376 \\
\hline 2 & 38.55 & 112.72 & 1215 \\
\hline 3 & 50.54 & 108.25 & 1171 \\
\hline 4 & 22.70 & 153.85 & 1460 \\
\hline 5 & 20.71 & 159.03 & 1489 \\
\hline 6 & 18.58 & 168.00 & 1693 \\
\hline 7 & 25.59 & 173.09 & 1691 \\
\hline 8 & 33.62 & 170.64 & 1189 \\
\hline 9 & 29.92 & 203.09 & \\
\hline 10 & 26.72 & 254.60 & \\
\hline
\end{tabular}

3.1.1 The number average molecular weight $(\mathrm{Mn})$ relationship with acid value

Acid value, Logarithm of acid value, $\mathrm{Mn}$ and Logarithm of $\mathrm{Mn}$ was listed in the Table 2. According to the data of Table 2 we deduced equations and model curves. Figure 1 showed the model curve of $\mathrm{Mn}$ and Logarithm of acid value. The model curve of acid value and Logarithm of $\mathrm{Mn}$ was showed on Figure 2. Both the equation of Figure 1 and Figure 2 showed their related coefficient was low, so the two equation are unreasonable.

Table 2 the result of acid value, Logarithm of acid value, Mn and Logarithm of Mn

\begin{tabular}{|c|c|c|c|}
\hline Acid value & Logarithm of acid value & Mn & Logarithm of Mn \\
\hline 18.58 & 1.269045710 & 1489 & 3.172894698 \\
\hline 20.71 & 1.316180099 & 1460 & 3.164352856 \\
\hline 22.70 & 1.356025857 & 1171 & 3.068556895 \\
\hline 25.59 & 1.408070286 & 1693 & 3.228656958 \\
\hline 26.68 & 1.426185825 & 1517 & 3.180985581 \\
\hline 26.72 & 1.426836454 & 1187 & 3.074450719 \\
\hline 29.92 & 1.475961589 & 1189 & 3.075181855 \\
\hline 33.62 & 1.526597709 & 1691 & 3.228143608 \\
\hline 38.55 & 1.586024382 & 1376 & 3.138618434 \\
\hline 50.54 & 1.703635238 & 1215 & 3.084576278 \\
\hline
\end{tabular}

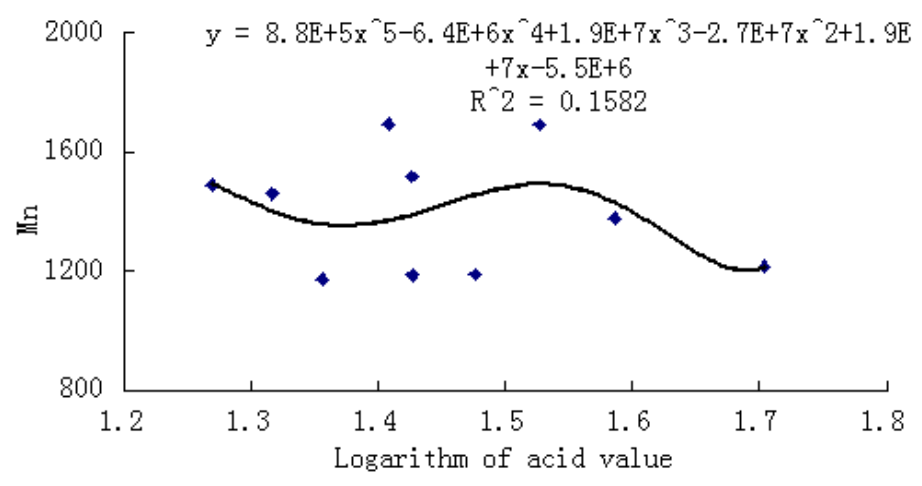

Fig 1: The model curve and equation of logarithm of acid value and $M_{n}$ 


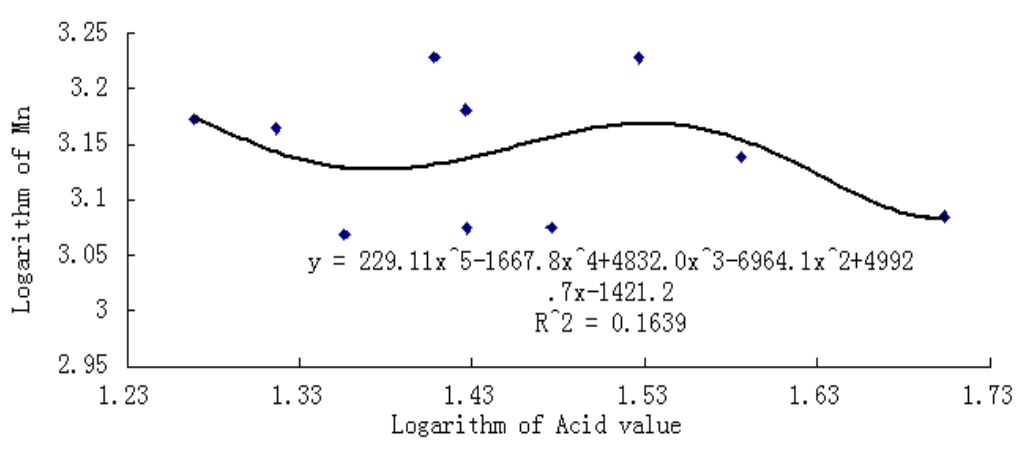

Fig 2: The model curve and equation of Logarithm of acid value and Logarithm of $\mathbf{M}_{\mathbf{n}}$

\subsubsection{The number average molecular weight $\left(M_{n}\right)$ relationship with hydroxy value}

Hydroxy value, Logarithm of hydroxy value, $M_{n}$ and logarithm of $M_{n}$ was listed in Table3.The model curve and calculate equations were on the Fig 3 and Fig 4. Fig 3 showed the model curve and equation of Logarithm of hydroxy value and $M_{n}$. Its related coefficient was 0.8754 . The model curve and equation of Logarithm of hydroxy value and Logarithm of $M_{n}$ was shown in Fig 4, its related coefficient was 0.9137 which was higher than Fig 3 . Consequently, the model curve and equation of Logarithm of hydroxy value and logarithm of $M_{n}$ was more reliable than logarithm of hydroxy value and $M_{n}$.

Table3: The data of hydroxy value, Logarithm of hydroxy value and $M_{n}$

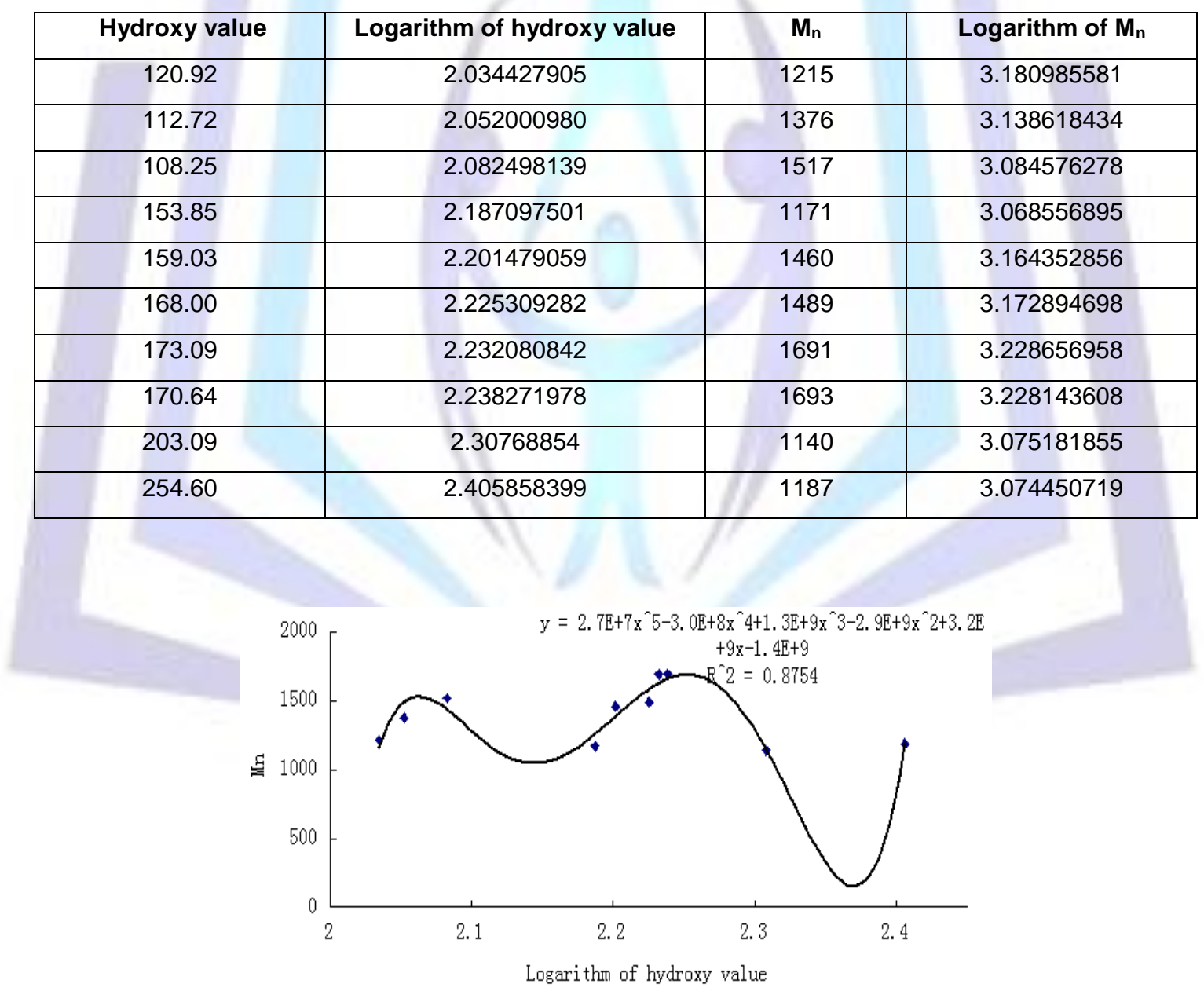

Fig 3: The model curve and equation of logarithm of hydroxy value and $M_{n}$ 


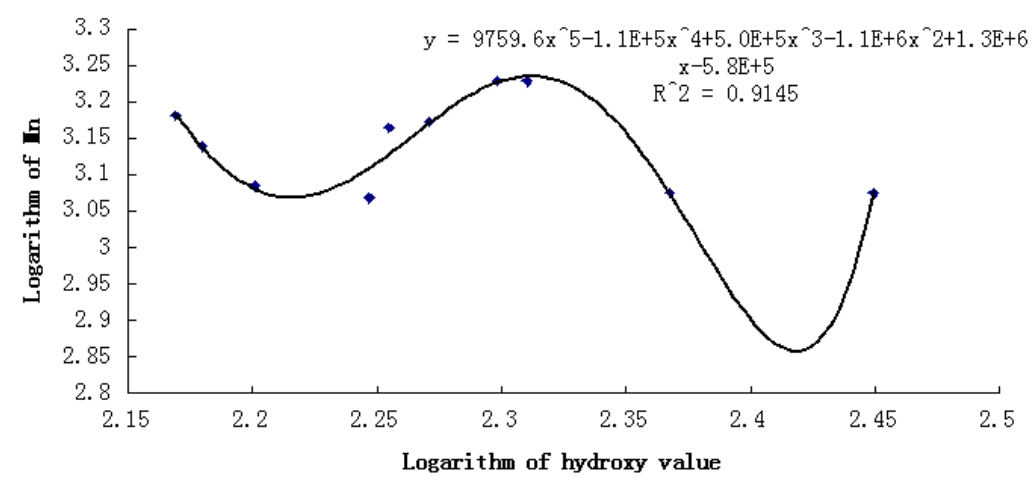

Fig 4: The model curve and equation of logarithm of hydroxy value and logarithm of $\mathbf{M}_{\mathbf{n}}$

3.1.3 The number average molecular weight $\left(M_{n}\right)$ relationship with the correct hydroxy value

The correct hydroxy value and Logarithm of the correct hydroxy value and $M_{n}$ was listed in table 4.The model curve and equation were shown on the Fig 5 and Fig 6, respectively.

Table 4 The result of the correct hydroxy value, Logarithm of the correct hydroxy value and Mn

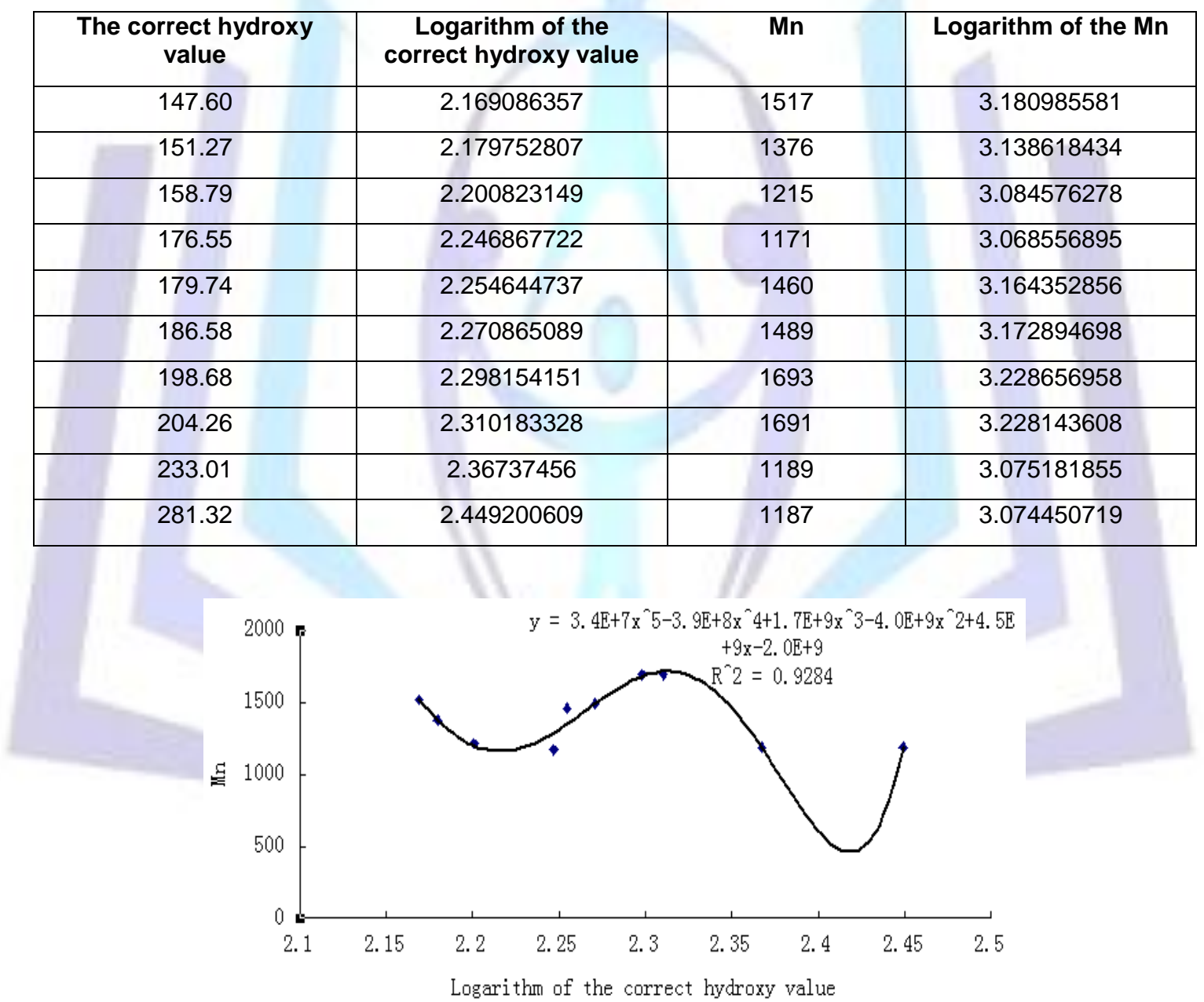

Fig 5: The model curve and equation of logarithm of the correct hydroxy value and $M_{n}$

Fig 5 showed the model curve and equation of Logarithm of the correct hydroxy value and Mn, its equation related coefficient $R^{2}$ was 0.9284 and the value was higher than the Fig 6 equation related coefficient $R^{2}$ i0.9145, the related coefficient of Fig 6 was smaller than Fig 5, but It was higher to Fig 4. Therefore, the model curve and equation of the correct hydroxy value is reasonable. The model curve and equation of Logarithm of the correct hydroxy value and Logarithm of $M_{n}$ is smallest of all. 


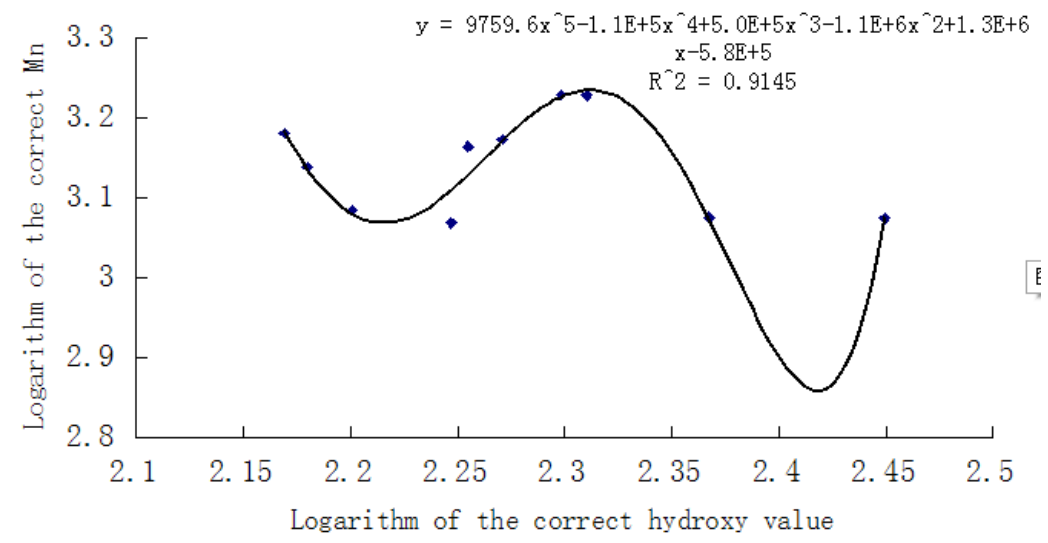

Fig 6: The model curve and equation of logarithm of the correct hydroxy value and logarithm of $M_{n}$

\subsubsection{NMR}

The ${ }^{1} \mathrm{H}$ NMR and ${ }^{13} \mathrm{C}$ NMR spectra of the hyperbranched polyester were respectively showed in Fig 7 and Fig 8.

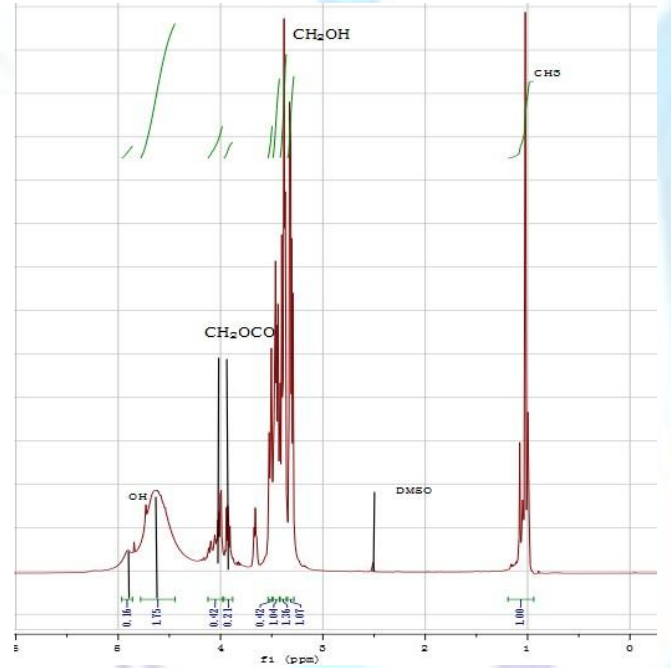

Fig 7: The ${ }^{1} \mathrm{H}$ NMR spectrum of the hyperbranched polyesters

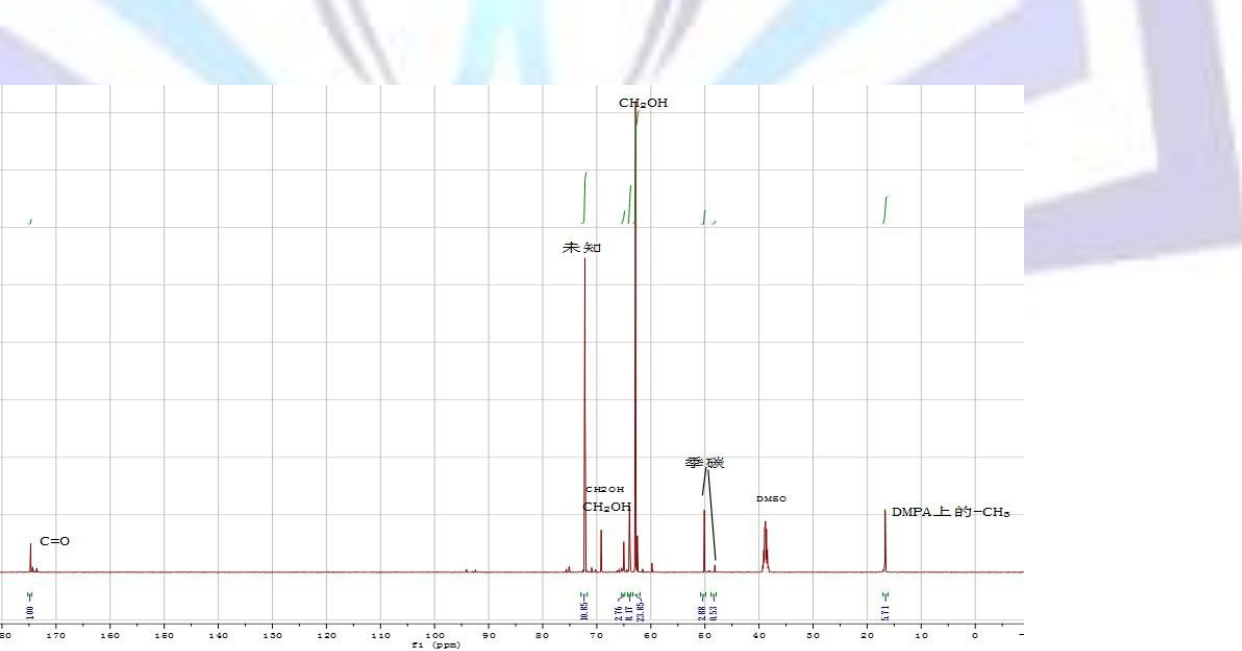

Fig 8 : The ${ }^{13} \mathrm{C}$ NMR spectrum of the hyperbranched polyesters

\section{CONCLUSION}

Above all, the model curve and equation of Logarithm of the correct hydroxy value and logarithm of $\mathrm{Mn}$ is optimum equation to calculate the $M n$ by acid value and hydroxy value. It's equation is $M n=9756.6 x^{5}+8 x^{4}+9 x^{3}+9 x^{2}+9 x-18,(x=a c i d$ value $y=$ hydroxy value) It's related coefficient $R^{2}$ is 0.9284 . 


\section{ACKNOWLEDGMENTS}

We gratefully acknowledge the financial support from Zhejiang Provincial Top Key Discipline of New Materials and Process Engineering(Grant NO.20121112) and Science \& Technological Project of Zhejiang, China (Grant NO.2013C31129) andthe Science \& Technological foundation of Wenzhou China ( Grant NO.H20100008)

\section{REFERENCES}

[1] Kim Y H.J.1998.Water-soluble hyperbranched polyphenylene,a unimolecular micelle.Polym Sci A: Polym Chem (1998)36:1685-1698

[2] Uhrich K.1997.Hyperbranched polymers for drug delivery.Trends Polym Sci (1997)5:388-393 .

[3] Gittins PJ, Twyman LJ,2003.Dendrimers and supramolecular chemistry.Supramol Chem(2003) 15:5-23 .

[4] Gao C ,Yan D.2004. Hyperbranched polymers: from synthesis to applications.Prog Polym Sci (2004)29:183-275 .

[5] A Trinchi and TH Muster.2007.A Review of Surface Functionalized Amine Terminated Dendrimers for Application in Biological and Molecular Sensing. Supramol Chem 19:431-445 .

[6] Duncan R,Izzo L,2005,Dendrimer biocompatibility and toxicity.Adv Drug Deliv Rev(2005) 57:2215-2237 .

[7] Malmstram.E,Johansson.M.and Hutt, A.1995.Hyperbranched Aliphatic Polyesters .Macromolecules (1995)28:16981703.

[8] Perce.V,Kawasumi M.Synthesis and characterization of a thermotropic nematic liquid crystalline dendrimeric polymer Macromolecules 25:3843(1992).

[9] K.E Uhrich,S.Boegeman,J.MJ.Frechet,.S.R.Turner,1997.The solid-phase synthesis of dendritic polyamides.Polymer. Bull.

[11] Frecht, J. M.,Tomalia, D. A.2001.Dendrimers and Other Dendritic Polymers; Wiley: New York.

[12] Tomalia DA and Frechet JM.J.2002.Discovery of dendrimers and dendritic polymers:a brief historical perspective.J Polym Sci A: Polym Chem(2002)40:2719-2728.

[13]Frechet J.M.1994.Functional Polymers and Dendrimers:Reactivity,Molecular Architecture and Interfacial Energy,Science(1994)263:1710-1715

[14] Yang G,JikeiM and Kakimoto M,Synthesis and properties of novel aromatic hyperbranched polyamide prepared by direct polycondensation.1998 Proc Jpn Acad Ser B: Phys Biol Sci 74:188-191

[15] Jikei M, Fujii K, Yang G and Kakimoto M.2000.Synthesis and properties of hyperbranched aromatic poly amide copolymers from $A B$ and $A B_{2}$ monomers by direct poly condensation. Macromolecules.33:6228-6234

[16] In I, Lee H and Kim SY, Synthesis of Hyperbranched Poly(phenylene oxide) by Ullmann Polycondensation and Subsequent Utilization as Unimolecular Micelle.2003.Macromol Chem Phys204:1660-1664

[17]Kudo H, Maruyama K, Shindo S, Nishikubo T and Nishimura I,Syntheses and properties of hyperbranched polybenzoxazole by thermal cyclodehydration of hyperbranched poly[o-( $t$-butoxycarbonyl)amide] via $A_{2}+B_{3}$ approach. 2006.Polym Sci A: Polym Chem 44:3640-3649

[18] Wenxng Wang,Deyue Yan,Daniel Bratton and Qiang Wang .2003.Charge Tranfer Complex Inimer: A Facil Route to Dendritic Materials ,Adv Mater.15:1348-1352

[19] Matyjaszewski K,Mechanistic and synthetic aspects of atom transfer radical polymerization.1997.J Macromol Sci A A34:1785-1801

[20] Liu BL, Kazlauciunas A, Guthrie JT and Perrier S,2005.One-Pot Hyperbranched Polymer Synthesis Mediated by Reversible Addition Fragmentation Chain Transfer (RAFT) Polymerization.Macromolecules(2005) 38:2131-2136 .

[21] Kishore K. Jena etc.2007. Hyperbranched Polyesters: Synthesis,Characterization,and Molecular Simulations.J. Phys. Chem.(2007)111,8801-8811

[22] ISO 2554-74, Plastics-Unsaturated polyester resins-Determination of hydroxy value. 